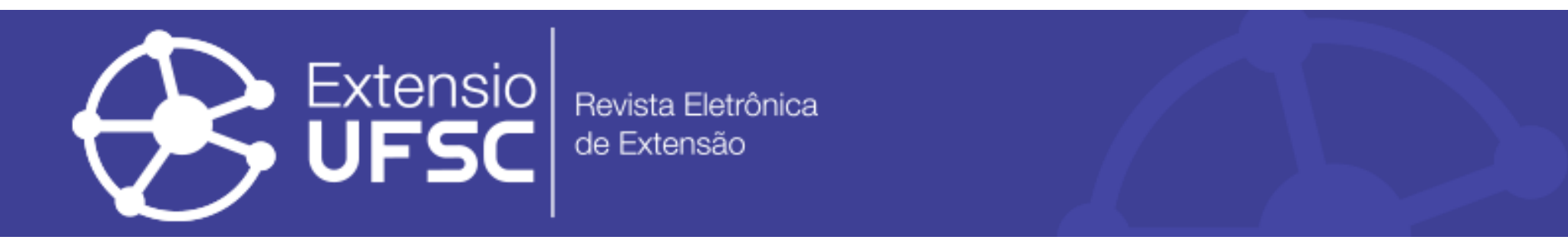

\title{
CENÁRIO DOS PROJETOS DE EXTENSÃO EM SECRETARIADO EXECUTIVO NA UNIVERSIDADE FEDERAL DE SANTA CATARINA
}

\author{
Katia Denise Moreira \\ Universidade Federal de Santa Catarina \\ katia.denise@ufsc.br \\ Juliana Cidrack Freire do Vale \\ Universidade Federal de Santa Catarina \\ juliana.cidrack@ufsc.br
}

\author{
Luci Mari Aparecida Rodrigues \\ Universidade Federal de Santa Catarina \\ luci.mari@ufsc.br \\ Stefani de Souza \\ Universidade Federal de Santa Catarina \\ stefani.souza@ufsc.br \\ Gabriela Mattei de Souza \\ Universidade Federal de Santa Catarina \\ gabriela.mattei@ufsc.br
}

\section{Resumo}

Considerada a importância da extensão universitária, uma vez que é ela parte indissociável do tripé universitário, este estudo objetivou investigar como se caracterizam os projetos de extensão universitária, realizados no âmbito da graduação em Secretariado Executivo da UFSC. Por meio de uma abordagem qualitativa, foi realizado um estudo documental e descritivo. Verificou-se que a realização de eventos acadêmicos voltados ao Secretariado predomina como atividade central nos projetos de extensão, fato considerado aquém do conceito de extensão proposto pelo FORPROEX. Outra apuração foi a de que houve preocupação em desenvolver uma interação dialógica entre os participantes; no entanto, no que se refere a outros indicadores da extensão, como interdisciplinaridade e interprofissionalidade, indissociabilidade entre ensino, pesquisa e extensão, impacto na formação do estudante e impacto e transformação social, não foram encontrados indícios de proximidade entre o realizado e o proposto por tais categorias.

Palavras-chave: Gestão Universitária. Projetos de Extensão Universitária. Curso de Graduação Secretariado Executivo.

\section{SCENARY OF EXTENSION PROJECTS IN EXECUTIVE SECRETARIAT AT FEDERAL UNIVERSITY OF SANTA CATARINA}

\begin{abstract}
Considering the importance of Extension Programs, since it is an inseparable part of the university tripod, this study aimed to investigate the characterization of University Extension Projects in the scope of Executive Secretariat undergraduation at UFSC. Through a qualitative approach, a study was made using documentary and descriptive methods. It was verified that events' organization is the predominant activity in the projects, and this was considered a short of the concept of extension proposed by FORPROEX. Furthermore, there was concern in developing a dialogical interaction among the participants, however, with regard to other indicators of Extension, such as interdisciplinarity and interprofessionality, indissociability between teaching, research and extension, impact on student training and impact and social transformation, no evidence was found of proximity between the projects realized and the proposed by such categories.

Keywords: University Management. University Extension Projects. Undergraduation Course at Executive Secretariat.

\section{ESCENARIO DE LOS PROYECTOS DE EXTENSIÓN EN SECRETARIADO EJECUTIVO EN LA UNIVERSIDAD FEDERAL DE SANTA CATARINA}

\section{Resumen}

Considerada la importancia de la extensión universitaria, ya que es parte indisociable del trípode - enseñanza, investigación y extensión, este estudio objetivó investigar cómo se caracterizan los proyectos de extensión universitaria, realizados en el ámbito del Grado en Secretariado Ejecutivo de la UFSC. A través de un enfoque cualitativo, se realizó una investigación documental y descriptiva. Se verificó que la organización de eventos en el área de Secretariado predomina como actividad central en tales proyectos de extensión, hecho considerado por debajo del concepto de extensión propuesto por el FORPROEX. Otro hallazgo fue lo de que hubo preocupación en desarrollar una interacción dialógica entre los participantes, sin embargo, en lo que se refiere a otros indicadores de la extensión, como interdisciplinariedad e interprofesionalidad, indisociabilidad entre enseñanza, investigación y extensión, impacto en la formación del estudiante e impacto y transformación social, no se encontraron indicios de proximidad entre lo realizado y lo propuesto por dichas categorías.

Palabras clave: Gestión Universitaria. Proyectos de Extensión Universitaria. Grado en Secretariado Ejecutivo. 
Cenário dos projetos de extensão em secretariado executivo na Universidade Federal de Santa Catarina

\section{INTRODUÇÃO}

A gestão universitária envolve uma série de ações e cabe aos gestores a tarefa de organizálas, no sentido de promover seu objetivo fim, que abrange a aprendizagem, a produção do conhecimento e as ações comunitárias, conforme destacou Keller (1983). Em termos de instituições de ensino superior vale destacar, ainda, que muitos são os problemas enfrentados, principalmente pela complexidade que envolve o ambiente universitário e, também, porque, de acordo com Silva (2012), grande parte dos gestores não obteve formação específica para tal fim.

Todavia, acredita-se que aquele que se propõe a assumir a posição de gestor universitário está ciente de que é o encarregado por conduzir e promover ações que envolvam o tripé da estrutura universitária, ou seja, o ensino, a pesquisa e a extensão (RIBEIRO, 2013). No que se refere a este tripé, destaca-se que tal tríade é baseada na promoção de uma relação recíproca entre a universidade e a sociedade que a sustenta (BRASIL, 1999).

Nessa perspectiva, o foco desta pesquisa recai sobre a extensão universitária, que possui função essencial na formação, uma vez que funciona como elo entre as universidades e a sociedade, objetivando, além da formação acadêmica, a transformação de caráter social (NUNES; SILVA, 2011). Associada a ela, aborda-se a formação do secretário executivo, que, alicerçado a essa filosofia, vem procurando se estabelecer também por meio de projetos de extensão universitária.

A partir das considerações ora apresentadas, emerge a seguinte questão de pesquisa: como se caracterizam os projetos de extensão universitária, realizados no âmbito do curso de graduação em Secretariado Executivo da Universidade Federal de Santa Catarina (UFSC)? Para responder ao questionamento, tem-se por objetivo investigar como se caracterizam os projetos de extensão universitária, realizados no âmbito do curso de graduação em Secretariado Executivo da UFSC. Para tanto, buscou-se descrever os projetos de extensão realizados pelo curso de graduação desde o surgimento do curso e, na sequência, verificar a inserção de tais projetos no contexto do que se compreende por extensão universitária, conforme a literatura sobre o tema.

Considerada a importância da extensão para a tríade de gestão universitária, a realização da pesquisa se justifica por ser ainda hoje um fator emergente na área secretarial. Dessa maneira, acredita-se ser importante refletir sobre o tema, promovendo, assim, a discussão sobre a materialização dessa prática nos cursos de graduação em secretariado, colaborando para o desenvolvimento dos profissionais que realizam suas formações nesta área.

Em termos de estrutura, o estudo apresenta inicialmente esta introdução; após, o referencial teórico, que abrange a temática da gestão universitária, visto que o trabalho trata de 
Cenário dos projetos de extensão em secretariado executivo na Universidade Federal de Santa Catarina

um dos elementos essenciais desse contexto; em seguida são feitas algumas considerações sobre a própria extensão universitária e, alinhada a ela, o curso de graduação em Secretariado Executivo, que vem se engajando para inserir-se em tal segmento. Posteriormente é apresentada a metodologia empregada na realização do trabalho para então serem expostos os dados e resultados obtidos no estudo.

\section{REFERENCIAL TEÓRICO}

\subsection{O ATUAL CONTEXTO DA EXTENSÃO UNIVERSITÁRIA}

Algumas das maiores virtudes e expressões do compromisso social da universidade são identificadas por meio de suas ações de pesquisa, ensino e extensão, consideradas atividades fins do ensino superior. $O$ exercício de tais funções é solicitado como dado de excelência na graduação, fundamentalmente voltado à formação de um profissional cidadão relacionado com a apropriação e produção do conhecimento científico e compromissado ainda com a realidade social (MENEZES NETO, 1983). A extensão universitária, em específico, é uma forma de interação que deve existir entre a universidade e a comunidade na qual ela está inserida, uma espécie de ponte permanente entre a universidade e os diversos setores da sociedade (NUNES; SILVA, 2011).

Tal entendimento confirma o que foi apontado introdutoriamente sobre a extensão universitária, ou seja, que esta ação possui um importante papel no que se refere às contribuições, frente à sociedade, no sentido de se colocar em prática aquilo que é aprendido em sala de aula. A partir deste contato entre o aprendiz e a sociedade, geram-se benefícios para ambas as partes. Esse é o conceito básico de extensão: a Universidade e a sociedade proporcionando benefícios e adquirindo conhecimentos (RODRIGUES et al, 2013). Dessa maneira, observa-se que a atividade de extensão deve ser um dos principais componentes para o entendimento sobre qual é o papel do ensino superior, pois quando as necessidades forem naturalmente percebidas pela comunidade acadêmica e incluídas no seu fazer, a universidade cumprirá com a sua finalidade (SOARES, 2003).

No que se refere ao contexto brasileiro, ressalta-se que em 1987 foi criado um fórum de discussões no I Encontro Nacional de Pró-Reitores de Extensão das Universidades Públicas (FORPROEX), o qual, a partir de um amplo debate desenvolvido em seus encontros realizados entre os anos de 2009 e 2010, apresentou a extensão universitária como “[...] um processo 
Cenário dos projetos de extensão em secretariado executivo na Universidade Federal de Santa Catarina

interdisciplinar, educativo, cultural, científico e político que promove a interação transformadora entre Universidade e outros setores da sociedade (FORPROEX, 2012, p. 31)". No ano de 2012, o FORPROEX apresentou às universidades públicas e à sociedade brasileira uma Política Nacional de Extensão Universitária, dando materialidade ao compromisso das Universidades, com a transformação da Universidade Pública, no sentido de torná-la um instrumento de mudança social (FORPROEX, 2012).

Assim, foram elaboradas e pactuadas, no Fórum, diretrizes que devem orientar a formulação e implementação das ações de Extensão Universitária, as quais estão dispostas no Quadro 1:

\begin{tabular}{|c|c|}
\hline Diretriz & Objetivo \\
\hline Interação dialógica & $\begin{array}{l}\text { Orienta o desenvolvimento das relações entre a } \\
\text { Universidade e os setores sociais, marcadas pelo diálogo e } \\
\text { troca de saberes. Não se trata mais de somente repassar à } \\
\text { sociedade o conhecimento acumulado, mas de produzir, por } \\
\text { meio dessa interação, um novo conhecimento. }\end{array}$ \\
\hline Interdisciplinaridade e Interprofissionalidade & $\begin{array}{l}\text { Combinação de especialização e visão holísticas pode ser } \\
\text { materializada pela interação de modelos, conceitos e } \\
\text { metodologias oriundos de várias disciplinas e áreas de } \\
\text { conhecimento. }\end{array}$ \\
\hline Indissociabilidade Ensino-Pesquisa-Extensão & $\begin{array}{l}\text { As ações de extensão adquirem maior efetividade se } \\
\text { estiverem vinculadas ao processo de formação de pessoas } \\
\text { (ensino) e de geração de conhecimento (pesquisa). }\end{array}$ \\
\hline Impacto na formação do estudante & $\begin{array}{l}\text { A qualificação da formação do estudante, por meio do seu } \\
\text { envolvimento com as atividades extensionistas, depende } \\
\text { também, no âmbito interno das Universidades, de um } \\
\text { diálogo franco e permanente dos órgãos destinados ao } \\
\text { fomento de ações de extensão com os colegiados da } \\
\text { graduação e da pós-graduação, de forma a possibilitar a } \\
\text { aplicação efetiva das diretrizes de extensão universitária. }\end{array}$ \\
\hline Impacto e transformação social & $\begin{array}{l}\text { Essa diretriz reafirma a extensão como mecanismo por meio } \\
\text { do qual se estabelece a inter-relação da Universidade com os } \\
\text { outros setores da sociedade, com vistas a uma atuação } \\
\text { transformadora, voltada para os interesses e necessidades da } \\
\text { maioria da população e propiciadora do desenvolvimento } \\
\text { social e regional, assim como para o aprimoramento das } \\
\text { políticas públicas. }\end{array}$ \\
\hline
\end{tabular}

Quadro 1 - Diretrizes norteadoras da Extensão Universitária.

Fonte: Elaborado pelas autoras com base em Nogueira (2000).

Diante do exposto no Quadro 1 e, de acordo com Nunes e Silva (2011), é possível compreender que a extensão universitária é um processo que viabiliza a relação entre a universidade e a sociedade, que vai além de ser um laboratório ou um objeto de estudo ou um campo de pesquisas. Ou seja, segundo os autores, a universidade deve atentar para as demandas, reivindicações, anseios e saberes que provêm tanto da comunidade universitária propriamente dita, como daquela externa a ela. 
Cenário dos projetos de extensão em secretariado executivo na Universidade Federal de Santa Catarina

Considerando a importância de se mensurar a contribuição oferecida pelas ações extensionistas para a produção e transmissão do conhecimento e transformação social, o FORPROEX fez proposições para orientar a construção de um sistema de monitoramento e avaliação nacional, cujas dimensões são as seguintes: política de gestão; infraestrutura, relação universidade-sociedade, plano acadêmico e produção acadêmica.

Ainda no que se refere à avaliação, cabe ressaltar que a extensão universitária deve ser entendida como processo formativo, prospectivo e qualitativo, a ser mensurado por critérios objetivos (relatório, trabalho escrito, publicação ou comunicação) e subjetivos (compromisso, dedicação). Esse processo deve estar integrado à avaliação dos objetivos e metas do programa ou projeto extensionista, assim como à avaliação dos efeitos da participação do estudante e da equipe de trabalho (FORPROEX, 2016).

Considerando as peculiaridades de cada instituição, a avaliação da extensão deve abordar três níveis inter-relacionados: a) o compromisso institucional para a estruturação e efetivação das atividades de extensão; b) o impacto das atividades de extensão junto aos segmentos sociais que são alvos ou parceiros dessas atividades e c) os processos, métodos e instrumentos de avaliação das atividades de extensão. O Quadro 2 ilustra os indicadores de cada nível.

\begin{tabular}{|c|c|}
\hline Níveis Inter-relacionados & Indicadores \\
\hline \multirow{9}{*}{ Compromisso institucional } & Grau de formalização da extensão na estrutura universitária. \\
\hline & $\begin{array}{l}\text { Definição clara das políticas institucionais, com explicitação de metas e } \\
\text { prioridades. }\end{array}$ \\
\hline & Conceituação e tipologia das atividades de extensão. \\
\hline & \begin{tabular}{|l} 
Existência de sistemas de informação sobre as atividades desenvolvidas. \\
\end{tabular} \\
\hline & Grau de participação da extensão no orçamento da universidade. \\
\hline & Grau de valorização nas carreiras docente e técnico-administrativa. \\
\hline & Existência de programas institucionais de fomento às atividades de extensão. \\
\hline & O envolvimento dos docentes nas atividades. \\
\hline & $\begin{array}{l}\text { A interação das atividades de extensão com o ensino e a pesquisa e a inserção das } \\
\text { atividades de extensão nos programas departamentais. }\end{array}$ \\
\hline \multirow{6}{*}{$\begin{array}{c}\text { Impactos sociais das } \\
\text { atividades }\end{array}$} & Relevância social, econômica e política dos problemas abordados nas instituições. \\
\hline & Segmentos sociais envolvidos. \\
\hline & Interação com órgãos públicos e privados e segmentos organizados. \\
\hline & Objetivos e resultados alcançados. \\
\hline & $\begin{array}{l}\text { Apropriação, utilização e reprodução, pelos parceiros, do conhecimento envolvido } \\
\text { na atividade de extensão. }\end{array}$ \\
\hline & Efeito da interação resultante da ação de extensão nas atividades acadêmicas. \\
\hline \multirow{9}{*}{$\begin{array}{l}\text { Processos, métodos e } \\
\text { instrumentos de avaliação } \\
\text { das atividades de extensão }\end{array}$} & Número de projetos envolvidos. \\
\hline & Público estimado. \\
\hline & Número de eventos realizados. \\
\hline & Público beneficiado. \\
\hline & Tipos de cursos de extensão realizados. \\
\hline & Número de certificados expedidos. \\
\hline & Número de produtos elaborados - CD's, vídeos, filmes, etc. \\
\hline & Prestação de serviço realizado. \\
\hline & Número de municípios atendidos em ações extensionistas. \\
\hline
\end{tabular}


Cenário dos projetos de extensão em secretariado executivo na Universidade Federal de Santa Catarina

\footnotetext{
Quadro 2 - Níveis e indicadores para avaliação da extensão.

Fonte: Elaborado pelas autoras com base em FORPREX (2012).
}

Diante do exposto, e conforme argumentam Fernandes et al (2012), sobre o princípio de que a formação do acadêmico é tomada como fundamento do processo educativo implementado na universidade, em que ao aluno é capaz de refletir sobre o aprendido em sala de aula e a vivência em outros espaços, como na comunidade, o Secretariado Executivo, alicerçado nessa filosofia, vem procurando se estabelecer também por meio da promoção de projetos de extensão universitária na construção do seu rol de competências.

\subsection{O SECRETARIADO EXECUTIVO E A EXTENSÃO UNIVERSITÁRIA}

De acordo com Barros, Silva e Barros (2015), vive-se um momento de construção de identidade científica no âmbito acadêmico em Secretariado, por meio da ampliação de estudos e pesquisas que, embora ainda em fase emergente, muito têm contribuído para a consolidação da área. Nessa perspectiva, destaca-se que os estudantes e professores do secretariado também têm se engajado para promover cada vez mais atividades de extensão, o que reflete a relevância dessa atividade para a formação acadêmica da área.

Essa afirmação se traduz por meio de estudos que começaram a ser realizados sobre a atuação dos estudantes e profissionais de secretariado em diversos projetos de extensão, os quais têm sido fundamentais para a materialização dessa prática, embora ainda exista um longo caminho a ser percorrido. Destaca-se a pesquisa realizada por Biscoli et al (2012), que descreveu a avaliação dos acadêmicos participantes de um projeto de extensão, "Preparando para o Primeiro Emprego", realizado na Universidade Estadual do Oeste do Paraná (UNIOESTE).

A pesquisa objetivou identificar as dificuldades encontradas e as perspectivas sobre novas propostas a serem oferecidas, bem como verificar até que ponto a "tomada de consciência" foi possibilitada por meio da extensão, pesquisa esta realizada por meio da aplicação de questionário junto aos vinte e quatro acadêmicos do curso de Secretariado Executivo, que estavam cadastrados no projeto (BISCOLI et al, 2012). Segundo os autores, o citado projeto, além de realizar a preparação para o primeiro emprego de jovens vinculados a instituições sem fins lucrativos, também buscou iniciar o acadêmico de Secretariado Executivo na pesquisa, na extensão e no ensino, incentivando-o a atuar como pesquisador, instrutor e ainda, a perceber o seu papel na sociedade.

Para tanto, os autores buscaram, na primeira parte do questionário, analisar o perfil dos acadêmicos participantes do projeto. Já na segunda parte, avaliaram a participação dos 
Cenário dos projetos de extensão em secretariado executivo na Universidade Federal de Santa Catarina

acadêmicos no projeto, tais como seus estímulos, dificuldades, interesses e envolvimentos. Como resultado, Biscoli et al (2012) observaram o afloramento do comprometimento dos acadêmicos com as questões sociais, além da preocupação com os resultados do projeto. Verificaram também que a falta de tempo da maioria dos entrevistados para dedicação a atividades extensionistas não foi impedimento para seu compromisso, constatando a intenção destes em continuarem em novos projetos dessa natureza.

Em estudo semelhante, realizado por Vaz, Oliveira e Stocco (2016), buscou-se identificar quais as efetivas contribuições que o projeto "Super'Ação: Secretariado vai à escola" proporcionou aos acadêmicos de Secretariado Executivo da Universidade de Passo Fundo (UPF) e qual a percepção destes em relação a essas contribuições. $\mathrm{O}$ objetivo do projeto era integrar os acadêmicos, os professores e a comunidade, por meio de palestras realizadas com alunos das escolas da rede pública local, abordando temáticas ligadas à formação do aluno do ensino médio no que concernia à sua preparação para o mercado de trabalho.

A pesquisa exploratória e descritiva foi aplicada com o uso de questionário, tendo como respondentes os alunos do terceiro ano do ensino médio de cinco escolas públicas estaduais de Passo Fundo (VAZ; OLIVEIRA; STOCCO, 2016). Segundo os autores, além de apresentar a importância da extensão universitária no aprendizado acadêmico, expondo as atividades do projeto, o estudo pretendeu principalmente avaliar as contribuições do projeto nessas escolas.

Nessa perspectiva, para o alcance dos objetivos mencionados, Vaz, Oliveira e Stocco (2016) aplicaram questionários compostos por cinco questões, duas discursivas e três objetivas, a saber:

1) O projeto "Super'Aç̃o: Secretariado vai à escola" contribuiu para a sua escolha profissional e pessoal? De que forma? 2) Você considera importante o desenvolvimento dos temas apresentados neste projeto? 3) Hoje, qual o seu nível de satisfação com a sua vida profissional? 4) Você considera-se motivado? 5) Escreva seus comentários e/ou sugestões (VAZ, OLIVEIRA, STOCCO, 2016, p. 108).

A pesquisa apresentou indicadores de que o projeto teve seu objetivo percebido por seus participantes, pois foi observado que, na maioria das respostas, as atividades eram produtivas e as percepções dos assuntos abordados contribuíram com a formação pessoal e profissional dos alunos. Assim, o resultado encontrado pelos autores evidenciou que a experiência da extensão universitária foi positiva, uma vez que contribuiu para o aprendizado dos acadêmicos e colaborou para o desenvolvimento de habilidades, como as de comunicação, comprometimento e relacionamento interpessoal (VAZ, OLIVEIRA, STOCCO, 2016). 
Cenário dos projetos de extensão em secretariado executivo na Universidade Federal de Santa Catarina

Ainda, outro estudo realizado por Azevedo et al (2011) teve como objetivo identificar os limites e possibilidades da contribuição da formação continuada para extensionistas no projeto de "Gestão da Satisfação do Cliente”, do Curso de Secretariado Bilíngue da Universidade Federal da Paraíba (UFPB). A pesquisa procurou identificar o que os acadêmicos extensionistas entendem por extensão; quais as bases pedagógicas que deveriam ser apreendidas por um facilitador extensionista; o que se compreendia por formação continuada; quais competências poderiam ou não ser alcançadas na formação continuada de um facilitador; como uma formação continuada para estudantes extensionistas poderia influenciar a iniciação docência e quais as contribuições da formação continuada para sua atuação como facilitador em um curso de extensão (AZEVEDO et al, 2011).

$\mathrm{Na}$ análise dos dados obtidos por meio dos estudantes que faziam parte do grupo de extensionistas do projeto, os autores buscaram identificar os limites e possibilidades de contribuição da formação continuada. Assim, algumas competências pedagógicas foram estimuladas visando ao desenvolvimento destas pelos alunos enquanto facilitadores de curso de extensão na relação universidade-sociedade. A pesquisa resultou na possibilidade de preparação do discente na atuação como facilitador extensionista, por meio de aulas, promovendo o incentivo à iniciação docente (AZEVEDO et al, 2011).

Por fim, no trabalho realizado por Santos (2016), procurou-se apresentar as perspectivas teórico-metodológicas que têm fundamentado práticas secretariais em experiências vivenciadas em projeto de extensão do curso de Secretariado Executivo Bilíngue da UFPB. A autora apresenta o projeto de extensão Rede Educativa, Empreendedora e Colaborativa no Secretariado (Recosec), afirmando que ele surgiu como uma estratégia alternativa orientada ao empreendedorismo secretarial, constituindo uma rede de ações empreendedoras chamadas "células empreendedoras", visando:

\footnotetext{
Mobilizar sujeitos para a construção de Inventário de Atores da Cultura Popular, com o propósito de preservar o Patrimônio da Cultura Popular local, como também de promover articulação da Política Nacional de Patrimônio Cultural, em prol da ressignificação de expressões de cultura popular enquanto estratégia para o fortalecimento territorial, na perspectiva do desenvolvimento local sustentável da região do Vale do Mamanguape - PB (SANTOS, 2016, p. 184).
}

Com a realização da pesquisa, Santos (2016) acredita que os profissionais de Secretariado que tenham vivenciado, durante a formação acadêmica, a práxis secretarial no contexto de metodologias participativas atuarão profissionalmente com uma concepção diferenciada. Além disso, a autora afirma que terão chances de sair da "redoma empregatícia" pura e exclusivamente ditada pelo mercado, tendo também possibilidades de empreender e atuar como assessor 
Cenário dos projetos de extensão em secretariado executivo na Universidade Federal de Santa Catarina

interdisciplinar no âmbito dos órgãos e instituições de terceiro setor, voltados para as políticas públicas, agências de desenvolvimento, docência e educação, além de programas de extensão e movimentos sociais (SANTOS, 2016).

Diante do exposto, acredita-se que, de uma maneira geral, os resultados das pesquisas ora apresentadas evidenciam que há cursos de graduação em Secretariado Executivo que estão voltando suas ações acadêmicas para além do ensino e da pesquisa.

\section{PROCEDIMENTOS METODOLÓGICOS}

Em termos de estrutura metodológica, este estudo se ancora na abordagem qualitativa. No que se refere à natureza, o estudo é básico, uma vez que não haverá aplicação dos resultados (GIL, 1994) e, quanto aos objetivos, caracteriza-se descritivo, visto que tem como intuito descrever as características do fenômeno (DOXSEY; DE RIZ 2002-2003, p. 25).

A estratégia utilizada é a documental, que, de acordo com Saunders, Philip e Thornhill (2009), faz uso de registros teóricos (bibliográficos) e documentos como principal fonte de dados. Ressalta-se que há diferença entre definir a pesquisa documental como estratégia e como técnica de coleta de dados. Na primeira os dados são utilizados e analisados como elemento de atividades cotidianas. Fazem, portanto, segundo Saunders, Philip e Thornhill (2009), parte da realidade estudada e não são coletados originalmente como dados para fins de pesquisa. Dessa maneira, explicam os autores, permitem que as questões de pesquisa se alinhem entre o passado e as mudanças ao longo do tempo e, assim, sejam respondidas de forma exploratória, descritiva ou explicativa, neste caso, descritiva, limitadas pela natureza dos registros documentais.

Sob tal entendimento, este estudo tem o propósito de aprofundar uma realidade específica, que neste caso é aquela associada aos projetos de extensão que tiveram relação direta com o Curso de Graduação em Secretariado Executivo da UFSC. O recorte temporal é longitudinal com cortes transversais (VIEIRA, 2004), posto que se colheram os dados ao longo do tempo, mas com foco nos momentos em que foram realizados os projetos.

No tocante à coleta de dados, utilizou-se a pesquisa bibliográfica e documental. A primeira, realizada em livros e periódicos que estruturam o escopo teórico deste estudo. Observase que, a partir da seção que trata do Secretário Executivo e a extensão universitária, traçaram-se as categorias de análise, quais sejam, título do projeto, data de ocorrência, objetivo e resultados dos projetos de extensão realizados. Já com base na segunda, a pesquisa documental, extraíram-se os dados sobre os projetos de extensão da UFSC. 
Cenário dos projetos de extensão em secretariado executivo na Universidade Federal de Santa Catarina

Salienta-se que o material está inserido no banco de dados institucional "Notes UFSC", acessado pelo endereço: http://notes.ufsc.br/, em que as informações, ora apresentadas, foram descritas em concordância com o que foi disponibilizado pelos coordenadores dos projetos analisados. Nessa direção, o corpus da investigação alicerçou-se em de dez trabalhos, que foram analisados a partir de categorias analíticas alinhadas ao conceito de extensão e seus eixos norteadores, bem como em três projetos de extensão associados a cursos de graduação em Secretariado das universidades do Oeste do Paraná, Federal da Paraíba e Passo Fundo. Em continuidade, a próxima seção apresenta os resultados e discussões acerca do que foi levantado.

\section{APRESENTAÇÃO, ANÁLISE E DISCUSSÃO DOS DADOS}

\subsection{O CONTEXTO DA PESQUISA}

Na vertente ensino, a UFSC tem cerca de 30.000 discentes em nível de graduação, 7.000 em nível de pós-graduação, além de 6.000 no ensino a distância. Possui também o Colégio de Aplicação, que oferece ensino fundamental e médio, e o Núcleo de Desenvolvimento Infantil, atendendo crianças com menos de seis anos de idade. Sobre a pesquisa, apresenta 600 grupos certificados no Diretório de Grupos de Pesquisa do Conselho Nacional de Desenvolvimento Científico e Tecnológico (CNPq), envolvendo docentes, discentes e técnico-administrativos (UFSC, 2016c, n.p.).

Em relação à extensão, além dos trabalhos realizados dentro do país, possui atualmente convênios com mais de 50 países em todos os continentes, para cooperação com instituições de ensino ao redor do mundo. A extensão universitária tem um importante papel de integrar a sociedade com a universidade. Para isso, a UFSC possui uma Pró-Reitoria de Extensão (PROEX), criada em 2012 por meio da dissociação da Pró-Reitoria de Pesquisa e Extensão (PRPE) (UFSC, 2016d, n.p.).

De acordo com seu site de apresentação, a PROEX objetiva "articular e apoiar a execução da política de extensão da UFSC, seja através de ações específicas dos departamentos de ensino, seja através de ações institucionais, buscando uma integração mais efetiva da realidade social com as atividades realizadas na universidade" (UFSC, 2016d, n.p.). Além disso, a missão da PROEX é "contribuir para a concretização e o fortalecimento do papel social da UFSC através de ações de extensão, em conformidade com a Política Nacional de Extensão Universitária e o 
Cenário dos projetos de extensão em secretariado executivo na Universidade Federal de Santa Catarina

Fórum de Pró-Reitores de Extensão das Instituições de Educação Superior Públicas Brasileiras” (UFSC, 2016d, n.p).

Em termos de estrutura organizacional, a UFSC, Campus Sede, conta com onze Centros de Ensino, dentro dos quais está o Centro de Comunicação e Expressão (CCE), no qual se insere o Departamento de Língua e Literaturas Estrangeiras (DLLE), que aloca o Curso de Graduação em Secretariado Executivo, escolhido como objeto de estudo deste caso (UFSC, 2016b). O curso é caracterizado como interdisciplinar, ou seja, o currículo é composto por disciplinas que abrangem diversas áreas do saber. Nesse sentido, destaca-se que são onze os departamentos da UFSC envolvidos com a construção do conhecimento na área secretarial.

O curso de graduação em Secretariado Executivo é reconhecido pelo Decreto Federal n. ${ }^{\circ}$ 46.266, de 26/06/1959, publicado no Diário Oficial da União de 10/07/1959. Na UFSC, o curso é constituído por nove fases, distribuídas por semestres e percebe-se a tendência de uma formação para o mercado de trabalho, fato que pode ser aprimorado ao se aplicar a teoria tratada em sala de aula em experiências empíricas, ação que pode ser concretizada por meio de projetos de extensão universitária (UFSC, 2003).

\subsection{ANÁLISE E DISCUSSÃO DOS DADOS}

Conforme definido na sessão procedimentos metodológicos, este estudo irá, neste momento, apenas apresentar os dados referentes ao título do projeto de extensão, data de realização, objetivo e resultado, uma vez que se propõe investigar como se caracterizam os projetos de extensão universitária, realizados no âmbito do curso de graduação em Secretariado Executivo da UFSC, conforme ilustra o Quadro 3.

Quadro 3: Projetos de Extensão correlacionados ao curso de graduação em Secretariado Executivo.

\begin{tabular}{|c|c|c|c|}
\hline PROJETO & $\begin{array}{c}\text { DATA DE } \\
\text { REALIZAÇÃO }\end{array}$ & OBJETIVO & RESULTADO \\
\hline $\begin{array}{l}\text { Gestão de carreira e } \\
\text { empregabilidade na } \\
\text { área de Secretariado } \\
\text { Executivo }\end{array}$ & $\begin{array}{l}23 / 04 / 2008 \mathrm{a} \\
23 / 04 / 2008\end{array}$ & $\begin{array}{l}\text { Viabilizar o contato dos alunos com } \\
\text { profissionais da área, apresentando as } \\
\text { possibilidades de atuação no mercado de } \\
\text { trabalho, além das dificuldades e soluções } \\
\text { vivenciadas. }\end{array}$ & Evento realizado. \\
\hline
\end{tabular}




\begin{tabular}{|c|c|c|c|}
\hline $\begin{array}{l}\text { Primeiro encontro } \\
\text { de acadêmicos de } \\
\text { Secretariado } \\
\text { Executivo da UFSC }\end{array}$ & $\begin{array}{c}30 / 09 / 2010 \mathrm{a} \\
30 / 09 / 2010\end{array}$ & $\begin{array}{l}\text { Celebrar o dia do profissional de Secretariado } \\
\text { Executivo e dar oportunidade aos acadêmicos } \\
\text { da área de participar de atividades relacionadas } \\
\text { ao curso. }\end{array}$ & Evento realizado. \\
\hline $\begin{array}{l}\text { II Encontro de } \\
\text { Acadêmicos de } \\
\text { Secretariado } \\
\text { Executivo da UFSC }\end{array}$ & $\begin{array}{c}29 / 09 / 2011 \mathrm{a} \\
30 / 09 / 2011\end{array}$ & $\begin{array}{l}\text { Comemorar o dia do profissional de } \\
\text { Secretariado e promover o curso de Secretariado } \\
\text { da UFSC através de evento com palestrantes } \\
\text { convidados. }\end{array}$ & Evento realizado. \\
\hline $\begin{array}{l}\text { Congresso } \\
\text { Internacional do } \\
\text { Secretariado } \\
\text { Executivo }\end{array}$ & $\begin{array}{c}08 / 10 / 2011 \mathrm{a} \\
12 / 10 / 2011\end{array}$ & $\begin{array}{l}\text { Abrir espaço para discussão de questões } \\
\text { relacionadas à prática do profissional de } \\
\text { secretariado executivo; proporcionar a troca de } \\
\text { experiência entre os profissionais da área; servir } \\
\text { de fórum para discussões que subsidiem a crítica } \\
\text { dos currículos dos cursos de secretariado } \\
\text { executivo; servir de exercício prático aos alunos } \\
\text { do Curso de Secretariado Executivo da UFSC de } \\
\text { aplicação dos conhecimentos referentes à } \\
\text { organização de eventos, cerimoniais, } \\
\text { solenidades, protocolo, manuais e etiqueta. }\end{array}$ & Evento realizado. \\
\hline $\begin{array}{l}\text { II CONISE - } \\
\text { Congresso } \\
\text { Internacional de } \\
\text { Secretariado } \\
\text { Executivo }\end{array}$ & $\begin{array}{c}01 / 01 / 2012 \mathrm{a} \\
15 / 08 / 2012\end{array}$ & $\begin{array}{l}\text { Instigar discussão sobre diversos temas } \\
\text { relacionados ao desenvolvimento e ao bem-estar } \\
\text { dos secretários e secretárias executivas e, assim, } \\
\text { promover a integração e a disseminação de } \\
\text { conhecimento entre pesquisadores, estudantes e } \\
\text { profissionais que atuam na área. }\end{array}$ & Evento realizado. \\
\hline $\begin{array}{l}\text { III Encontro de } \\
\text { Acadêmicos de } \\
\text { Secretariado } \\
\text { Executivo da UFSC }\end{array}$ & $\begin{array}{c}27 / 09 / 2012 \mathrm{a} \\
28 / 09 / 2012\end{array}$ & $\begin{array}{l}\text { Comemorar o dia do profissional de } \\
\text { Secretariado e promover o curso de Secretariado } \\
\text { da UFSC através de evento com palestrantes } \\
\text { convidados. }\end{array}$ & Evento realizado. \\
\hline $\begin{array}{l}\text { CONUSEC } \\
\text { Congresso } \\
\text { Universitário de } \\
\text { Secretariado }\end{array}$ & $\begin{array}{c}24 / 06 / 2013 \mathrm{a} \\
05 / 08 / 2013\end{array}$ & $\begin{array}{l}\text { Abrir espaço para discussão de questões } \\
\text { relacionadas à prática do profissional de } \\
\text { secretariado executivo; proporcionar a troca de } \\
\text { experiência entre os profissionais da área; servir } \\
\text { de fórum para discussões que subsidiem a crítica } \\
\text { dos currículos dos cursos de secretariado } \\
\text { executivo; servir de exercício prático aos alunos } \\
\text { do Curso de Secretariado Executivo da UFSC de } \\
\text { aplicação dos conhecimentos referentes à } \\
\text { organização de eventos, cerimoniais, } \\
\text { solenidades, protocolo, manuais e etiqueta. }\end{array}$ & Evento realizado. \\
\hline $\begin{array}{l}1^{\mathrm{a}} \text { JORNADA DE } \\
\text { SECRETARIADO }\end{array}$ & $\begin{array}{c}01 / 10 / 2014 \mathrm{a} \\
02 / 10 / 2014\end{array}$ & $\begin{array}{l}\text { Espera-se com a realização do evento, que os } \\
\text { alunos do curso de Secretariado Executivo, que } \\
\text { irão participar como voluntários do projeto, } \\
\text { exercitem na prática as atividades de } \\
\text { planejamento e organização de eventos. }\end{array}$ & Evento realizado. \\
\hline $\begin{array}{l}\text { III CONISE - } \\
\text { Congresso } \\
\text { Internacional de } \\
\text { Secretariado } \\
\text { Executivo } \\
\end{array}$ & $\begin{array}{c}04 / 11 / 2014 a \\
04 / 11 / 2014\end{array}$ & Orientar os alunos para a preparação de eventos. & Evento realizado. \\
\hline $\begin{array}{l}\text { Organização do } \\
\text { evento } \\
\text { comemorativo para } \\
\text { o dia do profissional }\end{array}$ & $\begin{array}{c}01 / 10 / 2015 a \\
03 / 11 / 2015\end{array}$ & $\begin{array}{l}\text { Espera-se com a realização do evento, que os } \\
\text { alunos do curso de Secretariado Executivo, que } \\
\text { irão participar como voluntários do projeto } \\
\text { exercitem na prática as atividades de } \\
\text { planejamento e organização de eventos. }\end{array}$ & Evento realizado. \\
\hline
\end{tabular}


Cenário dos projetos de extensão em secretariado executivo na Universidade Federal de Santa Catarina

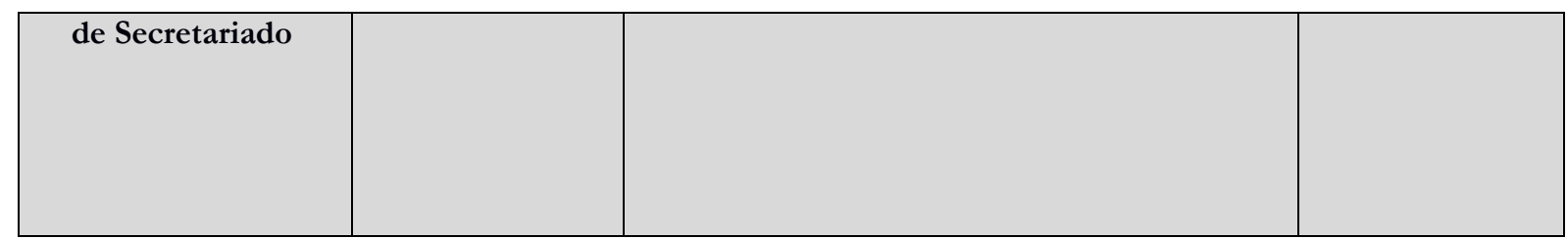

Fonte: Elaborado pelas autoras com base em UFSC (2016a).

A partir do exposto no Quadro 3, constatou-se que a metodologia utilizada em todos os projetos de extensão analisados foi a de organização de um evento, com a preparação e a realização de mesas-redondas, conferências e palestras. Observou-se também a tendência pela realização dos eventos em datas próximas ao dia 30 de setembro, data alusiva ao Dia do(a) Secretário(a). Assim, destaca-se a data de realização do evento Congresso Universitário de Secretariado (CONUSEC), ocorrido nos dias 24/06/2013 a 05/08/2013, supõe-se que em tal data tenha sido incluída também o período de organização do evento.

Ao se promover uma comparação entre o ilustrado no Quadro 3 e o dissertado na seção 2.3, verifica-se discrepância entre os projetos de extensão lá apresentados e aqueles realizados pelo Curso de Graduação em Secretariado Executivo da UFSC. Em outras palavras, nota-se que os projetos de extensão universitária realizados por cursos de graduação em Secretariado Executivo do Brasil pretendem uma interação diferenciada entre o graduando em Secretariado e a sociedade e não apenas a realização de um evento, focado na área, no qual apenas a comunidade secretarial tem participação efetiva, como no caso dos projetos de extensão em Secretariado do âmbito da UFSC.

Nota-se, também, que alguns coordenadores apenas reproduziram os objetivos de um evento anterior, fato que denota a não variação dos projetos de extensão. Outro elemento que merece ponderação são os resultados: no sistema não há menção alguma sobre tal momento, a não ser que o evento foi realizado. Vale destacar que um evento é composto pelas fases de préevento, trans-evento e pós-evento, cujas etapas poderiam ter sido descritas sucintamente no projeto considerando o tipo de atividade realizada em tais projetos [o evento] (MARTIN, 2015; MATIAS, 2001).

Em termos de alinhamento entre o conceito de extensão universitária proposto pelo FORPROEX (2012, p. 13), “[...] processo interdisciplinar, educativo, cultural, científico e político que promove a interação transformadora entre Universidade e outros setores da sociedade" e as informações disponíveis sobre os projetos em pauta, entende-se que o realizado está aquém daquilo que objetiva um projeto de extensão. Ao se analisar os dados sob a perspectiva dos eixos norteadores da extensão, também se pressupõe que se procurou 
Cenário dos projetos de extensão em secretariado executivo na Universidade Federal de Santa Catarina

desenvolver uma interação dialógica entre os participantes; no entanto, no que se refere aos outros indicadores - como interdisciplinaridade e interprofissionalidade, indissociabilidade entre ensino, pesquisa e extensão, impacto na formação do estudante e impacto e transformação social - não há indícios de proximidade entre o realizado e o proposto por tais categorias.

Por fim, diante dos dados apresentados, compreende-se necessário e relevante para a formação dos acadêmicos do Curso de Graduação em Secretariado Executivo da UFSC um pensar mais aprofundado sobre a extensão, ou seja, a realização de projetos ancorados tanto naquilo que define a extensão, quanto em seus norteadores. Sabe-se que se trata de um curso multidisciplinar, fato pelo qual as ações de extensão podem abranger diversos campos do saber, capacitando assim os acadêmicos para assumirem projetos mais audaciosos em termos de relacionamento entre a universidade e a sociedade, tais quais aqueles realizados por outros cursos de graduação em Secretariado, como na Universidade do Oeste do Paraná, na Universidade de Passo Fundo e na Universidade Federal da Paraíba, citadas neste estudo.

\section{CONSIDERAÇÕES FINAIS}

A extensão universitária deve atuar como elo entre a universidade e os diferentes setores da sociedade. Nesse sentido, a promoção de projetos de extensão universitária no âmbito de cursos de graduação em Secretariado Executivo pode oportunizar aos acadêmicos que conhecimentos aprendidos em sala de aula sejam colocados em prática, o que pode gerar benefícios tanto para o acadêmico quanto para a sociedade.

Considerado o foco da pesquisa, evidenciou-se que há cursos de graduação em Secretariado Executivo que estão voltando suas ações acadêmicas para além do ensino e da pesquisa, consolidando, assim, o tripé indissociável da gestão universitária. Porém, verificou-se discrepância entre os projetos de extensão realizados por cursos de graduação em Secretariado Executivo de outras Instituições de Ensino Superior do país e o curso da UFSC.

No espaço da UFSC demonstrou-se que a metodologia utilizada nesses projetos de extensão foi sempre a organização de evento, com mesas-redondas, conferências e palestras. Já os demais projetos de outras Instituições apresentados pretendem uma interação diferenciada entre o graduando em secretariado e a sociedade e não apenas a realização de um evento, focado na área, no qual apenas a comunidade secretarial tem participação efetiva. 
Cenário dos projetos de extensão em secretariado executivo na Universidade Federal de Santa Catarina

Dentre as limitações da pesquisa, cita-se a não realização de levantamento de campo, ou seja, não foram realizadas entrevistas com os coordenadores dos projetos, como também não foram aplicados questionários ao público participante dos eventos. Dessa forma, recomenda-se para estudos futuros um aprofundamento do tema, para que se possam buscar dados que permitam análise a partir dos eixos norteadores da extensão, com o intuito de fazer avançá-la no que se refere ao curso de graduação em Secretariado Executivo da Instituição ora investigada.

\section{REFERÊNCIAS}

AZEVEDO, E. T. C. et al. Extensão Universitária como incentivo para a prática de ensino por discentes: um estudo empírico no projeto de extensão do curso de Secretariado Executivo Bilíngue da UFPB. In: Encontro Nacional Acadêmico de Secretariado Executivo, 2, 2011, João Pessoa. Anais... João Pessoa: ENASEC, 2011.

BARROS, C. M. P.; SILVA, J. S.; BARROS, A. P. C. H. Ensino com pesquisa: contribuições para a cientificidade na formação em Secretariado Executivo. Revista de Gestão e Secretariado, v. 7, n. 1, p. 67-84, 2016.

BISCOLI, F. R. V. et al. A extensão universitária e os acadêmicos de Secretariado Executivo da Unioeste/Campus Toledo. Revista Conexão UEPG, v. 8, n. 2, p. 252-263, 2012.

BRASIL. Lei no 9.394, de 20 de dezembro de 1996. Estabelece as diretrizes e bases da educação nacional. Diário Oficial da República Federativa do Brasil, Brasilia, DF, de 23 de dezembro de 1996. Disponível em:

$<$ http://portal.mec.gov.br/seed/arquivos/pdf/tvescola/leis/lein9394.pdf> Acesso em: 24 jun. de 2016.

Ministério da Educação e do Desporto. Plano Nacional de Extensão Universitária. Brasília: MEC/CRUB, 1999. Documento do Fórum Nacional de Pró-Reitores de Extensão das Universidades Públicas Brasileiras.

CHAUÍ, M. A universidade pública sob nova perspectiva. Revista Brasileira de Educação, v. 24, p. 5-15, 2003.

DESIDERIO, M.; FERREIRA, A. P. F. Desafios de gestão universitária. Resumo. In: Simpósio de Excelência em Gestão e Tecnologia, 13, 2004, Resende. Anais... Resende: SEGe'T, 2004.

DOXSEY, J. R; DE RIZ, J. Metodologia da pesquisa científica. ESAB - Escola Superior Aberta do Brasil, 2002-2003. Apostila.

FERNANDES, M. C. et al. Universidade e a extensão universitária: a visão dos moradores das comunidades circunvizinhas. Educação em Revista, v. 28, n. 4, p. 169-194, 2012.

FORPROEX - Fórum de Pró-Reitores de Extensão das Universidades Públicas Brasileiras.

Política Nacional de Extensão Universitária. Disponível em: < https://www.ufmg.br/proex/renex/documentos/2012-07-13-Politica-Nacional-de-Extensao.pdf $>$ Acesso em: 24 jun. de 2016. 
Cenário dos projetos de extensão em secretariado executivo na Universidade Federal de Santa Catarina

GIL, A.C. Métodos e técnicas de pesquisa social. 4 ed. São Paulo: Atlas, 1994. 207 p.

GODOY, Arilda Schmidt. Pesquisa qualitativa: tipos fundamentais. Revista de Administração de empresas, v. 35, n. 3, p. 20-29, 1995.

KELLER, G. Academic strategy: the management revolution in American higher education. JHU Press, 1983.

MARTIN, V. Manual prático de eventos: gestão estratégica, patrocínio e sustentabilidade. 1.ed. Rio de Janeiro: Elsevier, 2015.

MATIAS, M. Organização de eventos: procedimentos e técnicas. 5.ed. Barueri: Manole, 2001.

MENEZES NETO, P. E. Universidade: ação e reflexão. Fortaleza: Edições UFC Imprensa Universitária, 1983.

MEYER JÚNIOR, V.; LOPES, M. C. B. Administrando o imensurável: uma crítica às organizações acadêmicas. Cadernos EBAPE.BR, v. 13, n. 1, p. 40-51, 2015.

NOGUEIRA, M. D. P. (Org.). Extensão universitária: diretrizes conceituais e políticas. Documentos básicos do Fórum Nacional de Pró-Reitores de Extensão das Universidades Públicas Brasileiras, 1987-2000. Pró-Reitoria de Extensão da Universidade Federal de Minas Gerais, 2000.

NUNES, A. L. P. F.; SILVA, M. B. C. A extensão universitária no ensino superior e a sociedade. Mal-Estar e Sociedade, v. 4, n. 7, p. 119-133, 2011.

RIBEIRO, R. M. C. Responsabilidade social universitária e a formação cidadã. Tese (doutorado) - Pontifícia Universidade Católica do Rio Grande do Sul, Faculdade de Educação. Programa de Pós-Graduação em Educação. Porto Alegre, RS, 2013.

RODRIGUES, A. L. L. et al. Contribuições da extensão universitária na sociedade. Caderno de Graduação-Ciências Humanas e Sociais-UNIT, v. 1, n. 2, p. 141-148, 2013.

SANTOS, M. L. C. A extensão-pesquisa e as metodologias participativas protagonizadas pela assessoria interdisciplinar. In: DURANTE, D. G; MARTINS, C. B.; CANTAROTTI, A. (orgs.). Pesquisa em secretariado: reflexões acerca da construção do conhecimento. Fortaleza: Edições UFC, 2016.

SAUNDERS, M.; LEWIS, P.; THORNHILL, A. Research methods for business students. 5. ed. New York: Prentice Hall Inc., 2009.

SILVA, F. M. V. A transição para a gestão universitária: o significado das relações interpessoais. Revista de Administração FACES Journal, v. 11, n. 4, p. 72-91, 2012.

SILVA, H. H. R.; SARRACENI, J. M. Gestão universitária: liderança e princípios pedagógicos. Universitária@-Revista Científica do Unisalesiano, ano 3, n. 6, p. 24-34, 2012.

SOARES, V. L. A. O papel social das IES: contribuição do ensino superior particular. Revista do Centro de Estudos Sociais Aplicados - Rev CESA, n. 6, p. 8, out. 2003.

UFSC. Universidade Federal de Santa Catarina. Currículo do Curso de Secretariado Executivo. 2003. Disponível em:

$<$ http:/ / cagr.sistemas.ufsc.br/relatorios/curriculoCurso?curso $=429 \&$ curriculo $=20032>$ Acesso em: 22 ago. 2016. 
Cenário dos projetos de extensão em secretariado executivo na Universidade Federal de Santa Catarina

Aplicações Notes. 2016a. Disponível em: <http://notes.ufsc.br/aplic/prjdaex.nsf> Acesso em: 22 ago. 2016.

Centro de comunicação e Expressão. Graduação. Florianópolis, 2016b. Disponível em: <http://www.cce.ufsc.br/cursos/>. Acesso em: 22 ago. 2016.

UFSC. Estrutura UFSC. 2016c. Disponível em: < http://estrutura.ufsc.br/>. Acesso em: 03 set. 2016.

PROEX - Pró-Reitoria de Extensão. 2016d. Disponível em:

$<$ http://proex.ufsc.br/>. Acesso em: 03 set. 2016.

VAZ, C. F. M.; OLIVEIRA, I. R.; STOCCO, J. A. P. A extensão universitária: percepções dos acadêmicos de Secretariado Executivo da UPF. In: Encontro Nacional de Estudantes de Secretariado, 8, 2016, Florianópolis. Anais... Florianópolis: ENESEC, 2016.

VIEIRA, M. M. F. Por uma boa pesquisa (qualitativa) em administração. In: VIEIRA, Marcelo Milano Falcão; ZOUAIN, Deborah Moraes. Pesquisa qualitativa em administração. Rio de Janeiro: FGV Editora, 2004. 